\title{
An Unusual Case of Tick Exposure: Tick in the External Auditory Canal
}

\author{
Mahmut Özkırış ${ }^{1}$, Çiğdem Kader ${ }^{2}$, Zeliha Kapusuz ${ }^{1}$ \\ ${ }^{1}$ Department of Otorhinolaryngologic Diseases, Bozok University Faculty of Medicine, Yozgat, Turkey \\ ${ }^{2}$ Department of Clinical Microbiology and Infectious Diseases, Bozok University Faculty of Medicine, Yozgat, Turkey
}

Ticks can carry and transmit numerous pathogens; most of these exist in our country, for example Crimean-Congo haemorrhagic fever (CCHF), rickettsial diseases, tularemia, $\mathrm{Q}$ fever, Lyme disease and anaplasmosis $(1,2)$. Ticks are found rarely in the external auditory canal and may lead to complications such as tick paralysis (2). In this case report, we aimed to emphasise the importance of careful physical examination of especially rare contact areas in the body for ticks in endemic areas and the importance of tick removal techniques.

A 27 year-old male patient was admitted with a 15 day history of pruritus, pain and the sense of a foreign body in the left ear. Otoscopic examination revealed a tick attached to the anterior-inferior part of the left external auditory canal. The external auditory canal was swollen and hyperaemic. The tympanic membrane could not be seen since the external auditory canal was blocked by the tick. It was observed that tick was a live half-fed female Hyalomma sp. (Figure 1). During history taking, it was learnt that the patient's occupation was farming and handling livestock, which might have been the source of the tick. The tick was successfully removed completely by extraction with alligator forceps and a small

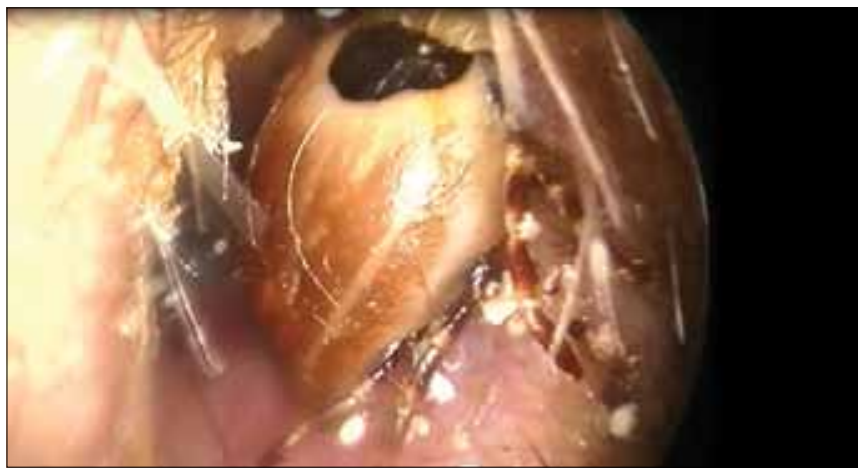

Figure 1. A half-fed female Hyalomma sp. tick in the left external auditory canal ear wax curette. The tympanic membrane was intact following the removal. After being informed about the possible signs of tick-borne infections, the patient did not show any signs of auditory canal infection or systemic disease such as CCHF during a 14 day follow-up period.

In conclusion, removal of ticks in the external auditory canal should be attempted only by experienced physicians to prevent complications. Tick removal should be performed as soon as possible because the risk of transmission of infectious agents increases significantly with the duration of attachment. The best and most successful tick-removal method is manual extraction. The tick should not be squeezed during removal as squeezing the tick may inject infectious material.

\section{Ethics Committee Approval: N/A}

Informed Consent: Informed consent was obtained from the patient who participated in the report.

Peer-review: Externally peer-reviewed.

Author contributions: Concept - Ç.K., M.Ö. ; Design - Ç.K.; Supervision - Ç.K. ; Resource - Ç.K.; Materials - M.Ö.; Data Collection\&/or Processing - Ç.K. ; Analysis\&/or Interpretation - Ç.K., Z.K.; Literature Search - Z.K.; Writing - Ç.K.; Critical Reviews - Ç.K., Z.K.

Acknowledgements: The authors would like to thank to Prof. Dr. Zati Vatansever for identifiying the type of the tick.

Conflict of Interest: No conflict of interest was declared by the authors.

Financial Disclosure: No financial disclosure was declared by the authors.

\section{References}

1. Erbay A. Crimean-Congo Hemorrhagic Fever Virus In: Liu D eds. Molecular detection of human viral pathogens. Boca Raton, FL, US: CRC Press Taylor and Francis Group, 2010: 617-629.

2. Doğan M, Devge C, Tanrı̈ver O, Pata YS, Sönmezoğlu M. Facial nerve paralysis due to intra-aural Hyalomma tick infestation. Turkiye Parazitol Derg 2012;36:254-7. 